\title{
Discusión de la metáfora ${ }^{1}$
}

\section{Discussion about the metaphor}

\section{Elena Sánchez-Mora ${ }^{2}$ San John's University}

\section{RESUMEN}

Este trabajo es una revisión teórica del concepto de metáfora, más allá de su concepción como figura retórica. El punto de partida es la recuperación de los conceptos de metáfora y metonimia, tal y como los concibe Jakobson, es decir, como términos dicotómicos no restringidos a la poesía, pero fundamentales para el análisis poético. En "Two Aspects of Language and Two Types of Aphasic Disturbances", Jakobson observa una preponderancia del proceso metafórico en las tendencias romántica y simbolista del arte y una preferencia por la metonimia en la tendencia realista. Se expone, también, la crítica de Ruegg y su análisis de la teoría de Lacan en torno a la metáfora. Se incluyen las aportaciones de Edeline a la relación metáfora-mito y de Cohen a la relación lógica-figuras

${ }^{1}$ Véase (1986, enero/junio). Semiosis, (16), pp. 3-22. Xalapa, Universidad Veracruzana. Actualizado.

${ }^{2}$ Elena Sánchez-Mora (México) es Doctora en Literaturas hispánicas y lusobrasileñas por la Universidad de Minnesota. Actualmente, es profesora del Departamento de Estudios Hispánicos en el College of Saint Benedict, San John's University (Minessota, USA). Sus estudios de Maestría en Historia y Maestría en Literatura los cursó en la Universidad Nacional Autónoma de México. Sus intereses académicos se centran en el feminismo y espiritualidad en la narrativa contemporánea de mujeres latinoamericanas; modelos feministas y espacios seguros en la literatura y el cine hispánicos. Ha estudiado novelas escritas por mujeres durante las décadas de los años sesenta a los noventa, en distintos países hispanoamericanos: México, Nicaragua, República Dominicana y Colombia. Ha publicado, entre otros, Integración versus individualización: incorporación de la pedagogía inclusiva en los cursos de lengua y cultura españolas (2017), La nueva mediadora: reconciliando feminismo y espiritualidad en la narrativa de mujeres latinoamericanas del siglo XX (2014), Utopia y praxis (1980). 
retóricas. Finalmente, se menciona la crítica de A. Johnson a Jakobson, seguida de un breve análisis de dos textos de Eco.

Palabras clave: Metáfora; metonimia; análisis poético; teoría literaria; géneros literarios.

\begin{abstract}
This work is a theoretical review of metaphor concept beyond its conception as a rhetorical figure. The starting point is the recovery of the concepts of metaphor and metonymy as conceived by Jakobson, that is, as dichotomous terms not restricted to poetry, but fundamental to poetic analysis. In "Two Aspects of Language and Two Types of Aphasic Disturbances", Jakobson observes a preponderance of metaphorical process in the romantic and symbolist tendencies of art and a preference for metonymy in the realist tendency. Ruegg's critique and his analysis of Lacan's theory around metaphor are also exposed. Edeline's contributions to metaphor-myth relationship and Cohen's to logic-figures of speech are included. Finally, A. Johnson's critique is made, followed by a brief analysis of two texts by Eco.
\end{abstract}

Key words: Metaphor; metonymy; poetic analysis; literary theory; literary genres.

El primer monumento de las literaturas occidentales, la Ilíada, fue compuesto hará tres mil años; es verosímil conjeturar que en ese enorme plazo todas las afinidades íntimas, necesarias (ensueño vida, sueño-muerte, ríos y vidas que transcurren, etcétera), fueron advertidas y escritas alguna vez. Ello no significa, naturalmente, que se haya agotado el número de metáforas; los modos de indicar o insinuar estas secretas simpatías de los conceptos resultan, de hecho, ilimitados.

Jorge Luis Borges, "La metáfora", Obras Completas 
Usando una metáfora para definir la metáfora, Borges ilustra la inagotabilidad, si no de lo metaforizable, de las maneras de metaforizar. Al parecer, también la discusión sobre el objeto y función de la metáfora tiende a ser, si no inagotable, por lo menos extremadamente compleja. En este trabajo, se partirá de las concepciones metafórica y metonímica aportadas por Jakobson, que constituyen una dicotomía no restringida a la poesía, pero fundamental para el análisis poético. En "Two Aspects of Language and Two Types of Aphasic Disturbances", Jakobson (1956, pp. 91-92) observa una preponderancia del proceso metafórico en las tendencias romántica y simbolista del arte y una preferencia por la metonimia en la tendencia realista. Dentro del aspecto teórico del trabajo, se explorará la teoría jakobsoniana según la expone el mismo Jakobson en dos textos claves en la teoría de la metáfora. Asimismo, se expondrá la crítica de Ruegg a dicha teoría y su análisis de la teoría de Lacan en torno a la metáfora. Se incluirán también aportaciones de Edeline a la relación metáfora-mito y de Cohen a la relación lógica-figuras retóricas. Finalmente, se hará mención de la crítica de A. Johnson a Jakobson, seguida de un breve análisis de dos textos de H. Eco.

Una vez expuestos los problemas que plantea la teoría jakobsoniana, se procederá, en una segunda parte, a demostrar empíricamente la validez de la idea de una dimensión dominante metafórica o metonímica mediante el análisis del texto poético "Walking around" de Neruda, que forma parte de Residencia en la tierra. Para terminar, se plantearán algunas conclusiones en cuanto a la aplicabilidad del esquema de Jakobson, recogiendo las consideraciones teóricas y el análisis concreto.

1. En Structuralism in Literature, R. Scholes (1974), antes de exponer la teoría de Jakobson, parte de dos distinciones aportadas por Saussure, que resultan cruciales tanto para la lingüística como para los estudios literarios, y en las que se basa la polaridad jakobsoniana. Son ellas la distinción entre sincronía y diacronía y la distinción entre relaciones sintagmáticas y paradigmáticas.

El significado de una palabra está determinado, en parte, por su relación con otras palabras, en un eje horizontal que constituye el aspecto sintagmático, diacrónico. El significado de una palabra 
también está determinado por su relación con otros grupos de palabras, que no aparecen en la oración, sino sólo se encuentran en una relación paradigmática -vertical, sincrónica. Jakobson aplicó las distinciones de Saussure a la poética, observando que la similaridad y la contigüidad se relacionaban con dos figuras retóricas básicas: la metáfora y la metonimia. Como se mencionó anteriormente, Jakobson identifica el romántico-simbolismo con la metáfora y el realismo con la metonimia. Con el objeto de tener a la vista esta serie de relaciones, se configura el siguiente esquema, en el que se continúa la serie de relaciones de Saussure con las de Jakobson:

\section{Tabla 1:}

\begin{tabular}{|l|l|}
\hline Saussure & \\
\hline $\begin{array}{l}\text { paradigmático (lo que no apare- } \\
\text { ce en el texto) } \\
\text { vertical (cambio) (presuposición, } \\
\text { intertextualidad) } \\
\begin{array}{l}\text { sincrónico (espacial) } \\
\text { (poesía) }\end{array}\end{array}$ & $\begin{array}{l}\text { sintagmático (lo que aparece en } \\
\text { el texto) } \\
\text { horizontal (progreso) (lectura li- } \\
\text { neal) } \\
\text { diacrónico (lineal) } \\
\text { (prosa) }\end{array}$ \\
\hline Jakobson & \\
\hline $\begin{array}{l}\text { metáfora } \\
\text { similaridad (analogía) } \\
\text { selección (in absentia) } \\
\text { Romántico-simbolismo }\end{array}$ & $\begin{array}{l}\text { metonimia } \\
\text { contigüidad (asociación) } \\
\text { combinación (in presentia) } \\
\text { Realismo }\end{array}$ \\
\hline
\end{tabular}

Elaboración propia

Maria Ruegg (1979), en su artículo "Metaphor and Metonymy: The Logic of Structuralist Rhetoric", hace una crítica a la "oposición binaria” de Jakobson entre metáfora y metonimia. Según Ruegg, dicha oposición binaria es un reflejo de la tendencia estructuralista a hacer generalizaciones universalizantes a partir de estructuras puramente hipotéticas, tendencia que, además de estar plagada de inconsistencias lógicas, revela el retorno de su pretendida revolución teórica a la retórica clásica. 
Ruegg encuentra, en cambio, que la aplicación de la distinción jakobsoniana por Lacan al contexto del sicoanálisis es más interesante y coherente, a pesar de estar localizada dentro de la tendencia estructuralista. En la terminología sicoanalítica de Lacan, la metonimia aparece como el deseo de ser sustituido por "El Otro", que es el verdadero objeto del discurso, su verdadero significado, mientras que la metáfora provee el acceso al reino de "El Otro", es decir, la metonimia constituye una transición hacia la metáfora; y en el paso de una a la otra, hay un progreso lineal: "la función de la metáfora es entonces revelar el 'verdadero discurso' del inconsciente" (Ruegg, 1979).

Si para Lacan la metáfora es el verdadero discurso, Edeline (1973) la percibe, en cambio, como falsa; y en el ejercicio de descifrarla está el descubrimiento de una verdad que se oculta tras una mentira (mito).

En última instancia, ambos autores ven la metáfora como una verdad ficticia y tranquilizadora, pero mientras Lacan se queda con esa verdad ficticia -es más, la busca para lograr una tranquilidad también ficticia-, Edeline se lanza a la búsqueda de la "verdadera verdad" tras la metáfora. En ambos esquemas, sin embargo, el hecho de que el verdadero sentido del significado se encuentre precisamente en lo que no aparece en el discurso coincide, por una parte, con el concepto Saussuriano de lo paradigmático en contraposición a lo sintagmático y, por otra parte, con el concepto de intertextualidad de Riffaterre (1982), en contraposición al concepto de lectura horizontal de Fish (1980).

Por su parte, Cohen (1982), basado en la idea de que la característica distintiva del lenguaje poético es la desviación como transgresión sistemática de la norma y en que la desviación lingüística y la lógica tienden a converger, intenta construir un modelo lógico de las figuras del lenguaje poético. Las figuras básicas de la retórica consisten en violaciones del principio de contradicción, que prohíbe la unión de una proposición y su negación. Tales figuras difieren entre sí solamente en cuanto a la fuerza o grado de dichas violaciones. A los términos polares de una contradicción se agrega el término neutro: de aquí, resultan formas débiles y fuertes de contradicción. 
Cohen distingue entre tropos y no-tropos. El tropo es usado en un sentido desviado, temporal y artificial. Cuando un sentido se vuelve usual, deja de ser un tropo. Una vez convenido lo que es un tropo, Cohen enfatiza la existencia de grados de desviación, de donde resulta que un tropo puede ser cercano o distante. Por ejemplo, una metáfora puede ser cercana o lejana según la distancia entre los dos sentidos. Si los clasicistas condenaron los tropos distantes, Cohen nota que la poesía moderna los ha adoptado como norma. Para explicar el valor estético de los tropos, Cohen afirma que éstos representan un regreso del intelecto a la sensibilidad básica del lenguaje. En suma, Cohen al explorar el dominio de la ciencia clásica de la retórica y cuestionar sus principios básicos, llega a la conclusión de que las figuras tienen gradaciones o matices y que las variantes dependen de factores como disyunción/conjunción, presuposición/aserción. Encuentra, por ejemplo, un alto grado de contradicción en el oxímoron y una contradicción débil en la antítesis. Según Cohen, la figura más frecuente en la poesía moderna es la llamada "irrelevancia predicativa", que establece una contradicción no a partir de lo que presenta, sino de lo que supone. Y aquí se insinúa un punto de contacto con la presuposición como forma modesta de la intertextualidad de Riffaterre y, nuevamente, con el nivel paradigmático de Saussure, todo lo cual parece sugerir que la poesía moderna, en términos de Cohen, se inclina hacia el lado de la metáfora, sin olvidar, por ello, que en Cohen metáfora y metonimia se diluyen en un sólo concepto: el de figura o tropo.

Permítasenos ahora formular un cuadro más, que resuma los planteamientos que hasta el momento se han citado, con el objeto de contrastarlos con el de Jakobson, alcanzando una primera fase en su evaluación como conceptos teóricos.

Tabla 2:

\begin{tabular}{|l|l|}
\hline Jakobson & Contradicción metáfora/metonimia \\
\hline Lacan & Triunfo de la metáfora ("verdad") \\
\hline Edeline & Metáfora = mito \\
\hline Cohen & tropos/no-tropos \\
\hline
\end{tabular}

Elaboración propia 
Se ha visto que la crítica de Ruegg a Jakobson se centra en su "oposición binaria" metáfora/metonimia. Dejando de lado el aspecto de la crítica de Ruegg en el sentido de inconsistencias lógicas y retorno a la retórica clásica, características del estructuralismo, enfoquemos la atención en los otros dos aspectos de la crítica: el que califica la distinción de Jakobson de estéril y la acusación de hacer generalizaciones universalizantes a partir de estructuras puramente hipotéticas. Si bien Ruegg tiene razón al afirmar que la característica distintiva del discurso poético es la de ser polisémico, es decir, la de transmitir mensajes ambiguos, es precisamente tal ambigüedad la que conduce a la elaboración de modelos abstractos que ayuden en su interpretación. También es cierto que toda abstracción puede llevar a una extremada -y por tanto, irreal- simplificación; sin embargo, el estar conscientes de que un modelo es una herramienta de trabajo para el análisis le confiere una determinada validez. Si una tipología no es otra cosa que un intento de hacer más accesible una realidad altamente compleja, la distinción jakobsoniana es válida en cuanto a que está dirigida a permitirnos un acercamiento al discurso poético. El problema aparece cuando los conceptos de metáfora y metonimia se ven como una contradicción irreconciliable. En cuanto a la construcción lacaniana, ya se ha visto que Ruegg le perdona el estar localizada dentro de la tendencia estructuralista, calificándola de más interesante y coherente. Aunque coincido con Ruegg en que la teoría de Lacan es ciertamente interesante, me pregunto qué aplicabilidad puede tener en el terreno del análisis poético una teoría que pretende -en palabras de Ruegg- proveernos de un código en términos del cual "todo discurso puede por fin ser verdaderamente comprendido". A pesar de que algunos de los términos freudianos en los que se centra el sistema filosófico de Lacan me parecen dudosos - "The phallus that mother never had"; "Father's law")-, creo que el planteamiento de la metáfora y la metonimia en términos psicoanalíticos ofrece elementos sugerentes. Tal vez lo que Ruegg ve de coherente en Lacan es su abierta aceptación de que su teoría es una manera de lograr una tranquilidad ficticia -si escuchamos a Fish, más vale una subjetividad consciente y controlada que una 
objetividad que proviene de la falsa ilusión-, pero lo que parece inaceptable es que, en nombre de esa coherencia ficticia, se hable de progreso lineal hacia un monismo totalizante. Si la polaridad de Jakobson carece de dinamismo, el monismo lacaniano parece aún más simplista.

Algo semejante se podría decir quizá de la identificación de la metáfora y el mito que hace Edeline, y que conduce a la búsqueda de una verdad única. Sin embargo, Edeline sugiere una serie de elementos que podrían resultar útiles en la práctica. El planteamiento central es el de la existencia de la poesía metafórica, en la que no se encuentran metáforas aisladas, sino "un todo metafórico en el que todos los términos de una misma columna son intercambiables y forman un mismo paradigma". El poema metafórico consiste, entonces, en una metáfora desarrollada o en "un conjunto de metáforas agrupadas según reglas invisibles pero estrictas". La poesía metafórica, según Edeline, es un delirio racional en el que el poeta identifica un razonamiento válido en el plano metafórico, con el plano de lo humanamente real. Esto reconcilia a la metáfora, identificada con el mito, con la realidad, pero es necesario desenmascararla. Lo anterior nos lleva posiblemente hacia una concepción más amplia de la metáfora, no como una simple figura retórica, sino como una actitud que, como quiere Jakobson, no se restringe a la poesía. En este sentido, se puede tal vez postular una poesía metonímica. Sin embargo, Edeline plantea la posibilidad de que la metáfora sea la estructura específicamente poética, tal como la estructura narrativa caracteriza el cuento y la novela.

Otro elemento que amplía el concepto de metáfora es la idea de que ésta se basa no sólo en la similitud de dos objetos, sino también en sus diferencias. A este respecto es importante el concepto de "clase límite", según el cual dos objetos pueden figurar juntos, aunque se separen en cualquier otra clase. ${ }^{3}$

El tercer elemento que proporciona Edeline es el proceso de desciframiento de una metáfora, que consiste en elaborar una cla-

${ }^{3}$ Un ejemplo de clase límite es rosa y muchacha. 
sificación analítica de dos objetos manifiestamente diferentes que presentan todas las marcas gramaticales de la equivalencia e incluso de la identidad, hasta agotar todas las diferencias entre ambos objetos. El enunciado de una metáfora debe tener una proporción adecuada de diferencias y semejanzas que depende del gusto personal del autor. Lo que hace que los términos de la oposición sean, a la vez, semejantes y diferentes es que éstos están articulados a lo largo de un eje semántico común. Hay, pues, una unidad oculta en lo diferenciado, que se restablece por la metáfora.

Frente al triunfo de la metáfora como verdad única, a su desciframiento como enmascaradora de la verdad y a la contradicción aparentemente irreconciliable de metáfora y metonimia, se nos presenta la dilución de ambos en el concepto de tropo de Cohen. A nivel de construcción teórica, tal vez sea la proposición de Cohen la que más se acerca a la realidad, ya que parece más convincente pensar en figuras con gradaciones o matices que en figuras excluyentes. Sin embargo, antes de descartar la construcción binaria de Jakobson examinémosla un tanto más detenidamente, a la luz de otro de sus críticos, Johnson, y de dos artículos de Eco.

En "Two Aspects of Language and Two Types of Aphasic Disturbances", Jakobson (1956) pretende ilustrar el proceso metafórico y el proceso metonímico a través de dos tipos de trastornos del lenguaje que se presentan con el padecimiento de la afasia. Este procedimiento ha suscitado la desaprobación de uno de los críticos de Jakobson: Anthony Johnson. Dice Johnson (1982):

Difícilmente puede uno dejar de preguntarse qué induce a Jakobson a creer que conceptos surgidos de condiciones pertinentes al deterioramiento de las facultades del lenguaje deberían ser directamente transferibles a condiciones que requieren un exceso de facultades del lenguaje con respecto a las cuales es suficiente asegurar una comunicación exitosa (p. 1). ${ }^{4}$

4 "One can hardly fail to wonder what induces Jakobson to believe that concepts grounded in conditions pertaining to the deterioration of language skills should be directly transferable to conditions calling for an over plus of language skills with respect to what is sufficient to ensure succesful communication." Las traducciones son mías, salvo indicación contraria. 
Otro aspecto de la crítica de Johnson es el de la aplicación de los conceptos de metáfora y metonimia a la conducta humana en general. En efecto, Jakobson (1956) afirma: "la dicotomía discutida aquí parece ser de significación y consecuencia primordiales para toda la conducta verbal y para la conducta humana en general" ( $p$. 93)..$^{5}$ A lo que Johnson (1982) objeta: "el uso de metáfora y metonimia como términos que designan procedimientos normales de asociación inevitablemente eclipsa la especificidad de la retórica al forzar su universalización" (p. 10). ${ }^{6}$

$\mathrm{Al}$ parecer, la razón de mayor peso que da pie a la crítica de Johnson es la de la trasgresión de los límites entre lingüística y poética. Si Jakobson (1960) afirma "el estudio lingüístico de la función poética debe traspasar los límites de la poesía, y, por otro lado, el escrutinio lingüístico de la poesía no puede limitarse a la función poética" (p. 357) y "un lingüista sordo a la función poética del lenguaje y un estudioso de la literatura indiferente a los problemas lingüísticos y poco versado en los métodos lingüísticos son anacronismos igualmente flagrantes" (p. 377), ${ }^{8}$ Johnson (1982) dice de Jakobson: "su terminantemente declarada integración de la literatura dentro de la lingüística... distorsiona la teoría y práctica de la interpretación literaria” (p. 38). ${ }^{9}$

Sin embargo, más allá de lo que parece ser una mera querella de límites entre dos disciplinas, sobresale la cuestión de la polaridad jakobsoniana. En "Two Aspects of Language and Two Types of Aphasic Disturbances”, Jakobson (1956), después de afirmar

5 "the dichotomy discussed here appears to be of primal significance and consequence for all verbal behavior and for human behavior in general."

6 "the use of metaphor and metonymy as terms naming standard procedures of association inevitably eclipses the specificity of rhetoric by for cibly universalizing it."

7 "the linguistic study of the poetic function must overstep the limits of poetry, and, on the other hand, the linguistic scrutiny of poetry cannot limit itself to the poetic function."

8 "a linguist deaf to the poetic function of language and a literary scholar indifferent to linguistic problems and unconversant with linguistic methods are equally flagrant anachronisms."

9 "his flatly stated integration of literature into linguistics... distorts the theory and practice of literary interpretation." 
que el hecho de que en la afasia una u otra de las operaciones del lenguaje esté restringida o bloqueada es lo que hace esclarecedor, para el lingüista, el estudio de este trastorno, confirma que en la conducta normal ambos procesos están continuamente operantes, para luego insistir: "pero la observación cuidadosa revelará que bajo la influencia de un patrón cultural, una personalidad y un estilo verbal, se da preferencia a uno de los dos procesos sobre el otro" (p. 90). ${ }^{10}$ Fijémonos en la palabra "preferencia". Por un lado, implica un acto que bien puede ser consciente o no y, por otro, podría indicar ya sea predominancia o dominancia absoluta. A este último sentido, parece referirse Johnson (1982) cuando habla del concepto jakobsoniano de "El Dominante". Aunque este concepto no se refiere específicamente a la metáfora y la metonimia, la crítica de Johnson (1982) a este concepto -“el arte verbal en su máxima intensidad tiende a ser difuso y orientado hacia la multiplicidad y no concentrado y unidireccional" (p. 47)- ${ }^{11}$ podría aplicarse, sin duda, a la relación que hace Jakobson entre simbolismo y metáfora y realismo y metonimia. Volvamos, ahora, al otro texto de Jakobson (1960) que hemos considerado, en donde se dice "En poesía, donde la similaridad se superpone a la contigüidad, toda metonimia es ligeramente metafórica y toda metáfora tiene un tinte metonímico" (p. 370). ${ }^{12}$ Observemos que mientras en la primera parte de esta cláusula la palabra "superimponer" implica dominancia de la metáfora en poesía, en la segunda el juego entre ambos procesos se torna más dialéctico. ¿Se trata de una contradicción constante e irresoluble o es posible que de la producción de "El Dominante" a "Two Aspects of Language and Two Types of Aphasic Disturbances", y luego "Closing Statement: Linguistics and Poetics", la teoría de Jakobson evolucionara de un totalitarismo hasta proponer una

10 "but careful observation will reveal that under the influence of a cultural pattern, personality, and verbal style, preference is given to one of the two processes over the other."

11 "verbal art at its most intense tends to be diffuse and multiply oriented rather than concentrated and unidirectional."

12 "In poetry where similarity is superinduced upon contiguity, any metonymy is slightly metaphorical and any metaphor has a metonymic tint". 
interacción? Quedémonos, por ahora, con la idea de la interacción, que es precisamente el problema que plantea Eco (1979) en "The Semantics of Metaphor".

Lo que Eco (1979) intenta mostrar es que no existe predominancia de la metáfora o la metonimia: "toda metáfora puede ser rastreada a una cadena subyacente de conexiones metonímicas." 13 Así pues, no hay polos, pero al emplear el verbo "rastrear" ¿no se está hablando de etapas y, por tanto, de evolución de la metonimia a la metáfora, hasta acercarse a la teoría lacaniana de la metonimia como transición a la metáfora en un progreso lineal en el que la función de la metáfora es proveer acceso al verdadero discurso? Por un lado, Eco parece descartar esta posibilidad, al afirmar "la querella entre metáfora y metonimia puede generar un vuelo hacia el infinito en el que un momento establece el otro, y viceversa"; ${ }^{14}$ por otro lado, dice: "El hecho es... que la sustitución tuvo lugar por la existencia en el código de conexiones y por lo tanto contigüidades. Esto nos llevaría a afirmar que la metáfora descansa sobre una metonimia." ${ }^{15}$ ¿Se está estableciendo una jerarquía? Al parecer, no hay contradicción entre metáfora y metonimia, pero tampoco completa interacción, o, por lo menos, no equitativa. ¿Es la metáfora una fase superior, pero que no puede existir sin la metonimia, es decir, depende de ella?

Uno de los factores en la teoría de Eco (1979) que parecen echar por tierra la bipolaridad jakobsoniana es que no considera similaridad y contigüidad como opuestos, sino complementarios, como en el ejemplo de nombrar la corona por el rey, explicado de esta manera: "hay una semejanza natural debida al hábito de contigüidad." ${ }^{16}$ La complementariedad de metáfora y metonimia

\footnotetext{
13 "each metaphor can be traced back to a subjacent chain of metonymic connections."

14 "the quarrell between metaphor and metonym can generate a flight to infinity, in which one moment establishes the other, and viceversa."

15 "The fact remains... that the substitution took place because of the existence in the code, of connections and therefore contiguities. This would lead us to state that metaphor rests on a metonymy."
}

16 "There is a natural resemblance, due to the habit of contiguity." 
es expresada en "The Scandal of Metaphor" de esta manera: "Es muy difícil en verdad considerar la metáfora sin verla en un marco que incluya necesariamente tanto la sinécdoque como la metonimia." 17

Si antes se había elegido la proposición de Cohen (1982), de considerar tropos con matices más que una figura predominante o figuras contradictorias, como la más acertada, después de analizar los planteamientos de Eco en torno a la metáfora y la metonimia como figuras al parecer no equivalentemente contradictorias, sino interdependientes, en medio de su diferenciación, creo poder concluir que, si bien éstos vienen a complicar las cosas todavía más -confirmándonos en su complejidad-, también echan una luz inesperada sobre el problema que nos ocupa, al afinar la noción de tropo a través de la metáfora vista como cadena metonímica. Pero esta luz nos lleva también a otro aspecto, que ya se planteaba hacia el principio de este trabajo. Me refiero a que, una vez aclarada la relación entre metáfora y metonimia, es preciso replantear la función de la metáfora, recordándose que se la había visto o bien como medio para llegar a la verdad única o como enmascaradora de la verdad. En ambos casos, la metáfora sustituía a la verdad, ya fuera ficticia o real. En este sentido, Eco agrega un elemento revelador al proponer la metáfora no como un instrumento sustitutivo del conocimiento, sino como un instrumento aditivo de éste. En "The Scandal of Metaphor", Eco (1983) rescata la noción aristotélica de la metáfora no sólo como medio de deleite, sino, sobre todo, como instrumento cognoscitivo. La forma como la metáfora actúa como tal es haciéndonos notar la similitud entre cosas diferentes, dentro de determinado contexto, ayudándonos, de paso, a conocer mejor dicho contexto. Un ejemplo es el que da Eco de la metáfora de las ovejas como noción de belleza dentro de la cultura judeo-cristiana, que plantea, a su vez, el problema de si la metáfora debe ser original o universal, concluyéndose que debe ser ambas. Otro ejemplo es el de la asociación de Dionisio con la copa, que

17 "It is very difficult indeed to consider the metaphor withouht seeing it in a framework that necessarily includes both synecdoche and metonymy." 
sólo se explica en la cultura griega. Podemos proponer, por nuestra parte, la consideración de que los poetas barrocos utilizan la metáfora para ocultar una realidad a la que no desean enfrentarse y lo hacen, por ejemplo, con la metáfora hiperbólica. La metáfora tendría, entonces, una función socio-histórica, al estar introducida en un contexto cultural determinado, pero lejos de dificultarnos el acceso a un código, nos lo abriría - ¿se acerca en esto Eco a la idea de figura poética de los ilustrados como mentira aparente que significa alguna cosa verdadera? Quedémonos, por lo pronto, con la idea de Eco de una metáfora como cadena de metonimias y como instrumento de conocimiento.

2. Walking around

Sucede que me canso de ser hombre.

Sucede que entro en las sastrerías y en los cines marchito, impenetrable, como un cisne de fieltro navegando en un agua de origen y ceniza.

El olor de las peluquerías me hace llorar a gritos. Sólo quiero un descanso de piedras o de lana, sólo quiero no ver establecimientos ni jardines, ni mercaderías, ni anteojos, ni ascensores.

Sucede que me canso de mis pies y mis uñas y mi pelo y mi sombra.

Sucede que me canso de ser hombre.

Sin embargo sería delicioso asustar a un notario con un lirio cortado o dar muerte a una monja con un golpe de oreja.

Sería bello

ir por las calles con un cuchillo verde y dando gritos hasta morir de frío. 
No quiero seguir siendo raíz en las tinieblas, vacilante, extendido, tiritando de sueño, hacia abajo, en las tripas mojadas de la tierra, absorbiendo y pensando, comiendo cada día.

No quiero para mí tantas desgracias.

No quiero continuar de raíz y de tumba, de subterráneo solo, de bodega con muertos, aterido, muriéndome de pena.

Por eso el día lunes arde como el petróleo cuando me ve llegar con mi cara de cárcel, y aúlla en su transcurso como una rueda herida, y da pasos de sangre caliente hacia la noche.

Y me empuja a ciertos rincones, a ciertas casas húmedas, a hospitales donde los huesos salen por la ventana, a ciertas zapaterías con olor a vinagre, a calles espantosas como grietas.

Hay pájaros de color de azufre y horribles intestinos colgando de las puertas de las casas que odio, hay dentaduras olvidadas en una cafetera, hay espejos que debieran haber llorado de vergüenza y espanto, hay paraguas en todas partes, y venenos y ombligos.

Yo paseo con calma, con ojos, con zapatos, con furia, con olvido, paso, cruzo oficinas y tiendas de ortopedia, y patios donde hay ropas colgadas de un alambre: calzoncillos, toallas y camisas que lloran lentas lágrimas sucias.

"No se puede revisar un texto y nombrar las figuras retóricas sin haber entendido el texto" (Culler, 1975). ${ }^{18}$ La afirmación de Culler

18 "One cannot go through a text and label rhetorical figures without having already understood the text." 
ilustra la situación que se encuentra al tratar de localizar metáfora y metonimia en un poema concreto. Tal es el caso de "Walking around" de Neruda. Aunque no exista una narrativa propiamente dicha, como en el caso de la novela o el cuento, se va estableciendo una especie de narrativa sui generis, que se puede seguir estrofa tras estrofa. Esto nos lleva al concepto de poesía metafórica, donde no encontraremos metáforas separadas, sino una metáfora desarrolla$\mathrm{da}$, que es, en última instancia, una forma de narrar condensada. Veamos cómo funciona.

El hecho de que el poema esté en primera persona nos habla de un sujeto que narra. Su presencia se refuerza por diferentes pronombres y adjetivos de primera persona. El tiempo presente de indicativo sugiere la serie de sensaciones físicas y acciones que experimenta el sujeto en movimiento. "Sucede que" establece una conclusión: todo sale de esa afirmación que se repite: me canso de ser hombre. La acción central es el paseo del narrador, que comienza al entrar en las sastrerías y en los cines: nos remite al título: "Walking around". ¿Qué clase de paseo es este? La palabra around nos da la clave: es un vagabundeo. En cuanto al entorno, es un medio urbano, con espacios cerrados: sastrerías, cines, peluquerías, hospitales, zapaterías, oficinas, tiendas de ortopedia. Son la representación de la organización social, pero su sentido es negativo: confinan al hombre. En ese paisaje urbano, el olor de las peluquerías hace llorar a gritos, los hospitales tienen ventanas por donde salen huesos, las zapaterías huelen a vinagre. En la segunda estrofa, se pasa del "sucede que..." al "sólo quiero..." Se pide una tregua, un descanso de piedras y de lana, algo natural en medio de este paisaje urbano asfixiante que hace que el narrador se vea a sí mismo como un cisne de fieltro, es decir, el cisne que ya no es el símbolo poético de la belleza de los modernistas, sino un cisne tieso, de juguete, que navega en un agua de origen: vida y ceniza: muerte. Vuelve, entonces, el "sucede que...", para decirnos que el hombre que pasea no está cansado sólo de lo que ve a su alrededor, sino de sí mismo, de su propio cuerpo.

En la estrofa cuatro, se rompe el tono personal y se convierte en impersonal; y se pasa del presente al condicional "sería", que 
condensa el deseo del narrador de acabar con la burocracia, representada por el notario, y la iglesia, por la monja. Pero esto no es posible, es hipotético.

En la estrofa cinco, se va del "sólo quiero..." al "no quiero...", que nos habla de un repudio hacia la muerte, que continúa en la estrofa siguiente. Lejos de ser el orden social, lo que ve el caminante es una imagen de caos, el caos en que se ha sumido el hombre. Es como una pesadilla o una visión apocalíptica en que se acumulan objetos sin relación alguna entre sí, lo cual los hace grotescos: horribles intestinos, dentaduras en una cafetera, ropas que lloran lágrimas sucias. Aquí, el tono es otra vez impersonal, usando "Hay..." para describir, aunque la presencia de la primera persona subsista.

En la última estrofa, se vuelve al yo. El narrador pasa de la calma a la furia, al olvido; reina la confusión. Pero sigue su paseo desolador, arrastrando los pies, como lo sugiere la aliteración de las letras. Entonces cobra pleno sentido lo que sugiere el caos, que, a pesar de todo, tiene un cierto orden, que habla de monotonía: la constancia del caos. Esta idea se refuerza mediante el ritmo desigual y a la vez sostenido, el énfasis en la sexta sílaba, la enumeración con comas, la repetición de conjunciones y preposiciones. ${ }^{19}$

Sigamos ahora el proceso de desciframiento de la metáfora que sugiere Edeline (1973), elaborando una clasificación analítica de los objetos, tratando de articularlos mediante un eje semántico común.

19 Para el análisis del texto de Neruda, se consultó a Amado Alonso (1940), Manuel Durán y Margery Safir (1981), Alfredo Lozada (1971). 
Tabla 3:

\begin{tabular}{|c|c|c|c|c|}
\hline \multicolumn{5}{|c|}{ VIDA HUMANA } \\
\hline \multicolumn{2}{|c|}{ NEGATIVO } & \multicolumn{3}{|c|}{ POSITIVO } \\
\hline \multicolumn{2}{|c|}{ SOCIAL } & \multicolumn{3}{|c|}{ NATURAL } \\
\hline Mercancias & Comercios & Tierra $=$ Muerte & Cuerpo & $\begin{array}{l}\text { Elementos } \\
\text { Inanimados }\end{array}$ \\
\hline mercaderías & sastrerías & raíz & pies & piedras \\
\hline anteojos & cines & tumba & uñas & lana \\
\hline ascensores & peluquerías & subterráneo & pelo & Seres Vivos \\
\hline paraguas & establecimientos & bodega & sombra & pájaros \\
\hline espejos & zapaterías & tierra & ojos & lirio \\
\hline cafetera & $\begin{array}{l}\text { tiendas de } \\
\text { ortopedia }\end{array}$ & & lágrimas & \\
\hline puertas & Instituciones & & intestinos & \\
\hline Prendas de vestir & Notario Monja & & huesos & \\
\hline calzoncillos & hospitales & & dentadura & \\
\hline camisas & oficinas & & & \\
\hline zapatos & calles & & & \\
\hline \multirow[t]{2}{*}{ zapatos } & casas & & & \\
\hline & jardines & & & \\
\hline
\end{tabular}

Elaboración propia

A continuación, veamos este esquema a la luz de la concepción de Eco (1983): de la metáfora como cadena de metonimias. ¿Es posible plantear que las series de palabras que designan realidades concretas nos conducen a la metáfora que propone el poema de Neruda: de una enajenación del hombre ante la realidad natural y la realidad social? Podría decirse, por ejemplo, que la proximidad de palabras como pies, uñas, pelo y sombra les confieren una similaridad o, más bien, que han sido puestas unas al lado de las otras por su similitud, en cuanto que nos sugieren partes de un todo que es el cuerpo humano, pero que han perdido su relación con ese todo. Tales palabras están conectadas por "sucede que me canso" y por la aliteración de Y, mis. ¿Se trata de una metáfora sugerida por la 
presencia de elementos metonímicos, mejor aún, de una cadena de metáforas constituidas por cadenas metonímicas, que, a su vez, forman parte de una metáfora que las en vuelve a todas y que es el poema mismo? Suponiendo que se acepte lo anterior, se podría postular en este poema la predominancia de un tipo de metáfora "in absentia", sugerida por cadenas metonímicas "in presentia", lo que daría la impresión de un predominio del elemento metonímico. Tal vez entonces, recuperando a Jakobson, se podría decir que este es un poema realista. Por otro lado, un poema simbolista sería aquél que funcionara a base de metáforas "in presentia", cuyo significado estaría dado por una serie de metonimias ausentes del poema, pero presentes en el código en que éste se sustenta. Por ejemplo, tomemos la metáfora de la vida como un río. Para descifrarla tendríamos que desarrollar un esquema en el cual una serie de elementos correspondientes a río correspondieran también a vida, encontrando que la clave es la característica de lo que fluye, que establece una relación de contigüidad semántica entre vida y río. Digamos que este es un poema en donde predomina la metáfora, porque es el elemento visible, lo cual no significa que no exista la cadena metonímica, sin la cual la metáfora no tendría sentido. Desde luego, para sostener esta idea tendríamos que analizar una serie de otros poemas, tomando también en cuenta que aun entre dos autores "realistas" habría diferencias entre el tipo de cadenas que conforman la metáfora.

Por ahora, digamos que Eco tiene razón en cuanto a postular la relación metáfora-metonimia y la idea de que la metáfora proporciona elementos de conocimiento. Y digamos también que Jakobson acierta, no en la oposición metáfora/metonimia, pero sí en la presencia concreta dominante de una u otra en un poema, y quizá en cuanto a que esa predominancia se encuentra en un tipo determinado de poemas. ¿Y por qué no decir también que Edeline acierta al identificar la metáfora con el mito y Lacan al verla como verdad ficticia, ya que, después de todo, todo poema es una totalidad ficticia? En ese caso, tampoco sería un contrasentido la identificación que hace Cohen de la metáfora con la poesía moderna o el planteamiento que hace Edeline de la metáfora como la estructura 
específicamente poética. Finalmente, si se acepta la hipótesis aquí postulada, se tendría que conceder validez a la extensión jakobsoniana de una actitud metafórica y otra metonímica ante la realidad, más allá de la poética. Imaginemos, por un momento, a una persona de inteligencia metonímica o realista, cuya reacción ante la realidad es partir de lo más concreto a lo más abstracto. Esta persona no sería, por ese hecho, afásica, ya que los dos procesos estarían presentes, pero en una composición diferente. En cambio, Jakobson sería metafórico, por partir de una metáfora -la de dos polos que conforman una cualidad irreconciliable-al tratar de aplicar esa tipología en la realidad, mientras que Aristóteles partiría de la realidad concreta para llegar a la abstracción. En la esfera de lo cotidiano, se dice que hay personas realistas e idealistas.

Volviendo al terreno poético, tal vez convenga mencionar aquí algunas ideas respecto a la relación entre el texto poético y el mundo. Riffaterre (1982) apunta que el texto poético se corta a sí mismo de una conexión referencial directa con la realidad, mientras que Scholes insiste que, en la mayoría de los casos, el texto poético vuelve, mediante alegoría, a la conexión referencial con la realidad. Cuando Scholes compara las ideas de Riffaterre y Lotman al respecto, encuentra que ambos autores notan que los textos poéticos desafían nuestros modos de hablar aceptados, pero en tanto que Lotman cree que esos desafíos conducen a un mayor entendimiento del mundo Riffaterre permanece escéptico. Scholes concluye que la cuestión no está solucionada, pero, por lo menos en el poema que aquí hemos analizado, nos parece que Scholes y Lotman describen más acertadamente la relación entre el texto poético y el mundo. En efecto, la metáfora del vagabundeo en "Walking around" nos conecta muy directamente con la experiencia del poeta de una enajenación de la realidad natural y social. 


\section{Bibliografía}

Alonso, A. (1940). Poesía y estilo de Pablo Neruda. Interpretación de una poesía hermética. Buenos Aires. Losada.

Cohen, Jean. (1982). A Theory of the Figure. En Tzvetan Todorov (Ed.), French Literary Theory Today, pp. 64-91. Cambridge. Harvard University Press.

Culler, J. (1975). Structuralist Poetics. Ithaca. Cornell University Press.

Durán, M. y Safir M. (1981). Earth Toner. The Poetry of Pablo Neruda. Indiana. Indiana University Press.

Eco, H. (1979). The Role of the Reader. Bloomington. Indiana University Press.

Eco, H. (1983). The Scandal of Metaphor. Poetics Today, 4(2), pp. 217-257.

Edeline, F. (1973). Campo analógico y estructura narrativa. En Francis Edeline y otros, Análisis estructural del texto poético. Buenos Aires. Rodolfo Alonso.

FIsH, S. (1980). Is There a Text in This Class? Cambridge. Harvard University Press.

Jakobson, R. (1960). Closing Statement: Linguistics and Poetics. En т. A. Sebeok (Ed.), Style in Language, pp. 350-377. Nueva York-Londres. The Technology Press of Massachusetts Institute of Technology and John Wiley \& Sons.

Jakobson, R. (1956). Two Aspects of Language and Two Types of Aphasic Disturbances. En Roman Jakobson \& Morris Halle, Fundamentals of Language. The Hague. Yale Mouton.

Johnson, A. (1982). Jakobsonian Theory and Literary Semiotics: Toward a Generative Typology of the Text. New Literary History, 14(1), pp. 33-61.

LozADA, A. (1971). El monismo agónico de Pablo Neruda. Estructura, significado y filiación de "Residencia en la tierra". México. Costa Amic.

Riffaterre, M. (1982). Models of the Literary Sentence. En Tzvetan Todorov (Ed.), French Literary Theory Today, pp. 18-33. Cambridge. Cambridge University Press. 
Ruegg, M. (1979). Metaphor and Metonymy: The Logic of Structuralist Rhetoric. Glyph, (6), pp. 141-157.

SCHOLES, R. Structuralism in Literature. New Haven. University Press. 